\title{
Covariate-based dose individualization of the cytotoxic drug indisulam to reduce the risk of severe myelosuppression
}

\author{
Anthe S. Zandvliet · Jan H. M. Schellens • \\ William Copalu · Jos H. Beijnen • \\ Alwin D. R. Huitema
}

Received: 24 May 2008/Accepted: 19 January 2009/Published online: 7 February 2009

(C) The Author(s) 2009. This article is published with open access at Springerlink.com

\begin{abstract}
Aim Chemotherapy with indisulam causes myelosuppression. This study aimed to evaluate the influence of patient-related covariates on pharmacokinetics and pharmacodynamics, to identify patients at risk for severe myelosuppression and to develop a dosing algorithm for treatment optimization. Methods Pharmacokinetic and pharmacodynamic data of 412 patients were available. Non-linear mixed effects modeling was used to determine the relative risk of dose-limiting myelosuppression for various covariates (demographics, physical condition, prior treatment, comedication, CYP2C genotype and biochemistry). Results Body surface area (BSA), race and CYP2C genotype had a significant impact on indisulam elimination $(P<0.001)$. Low BSA, Japanese race, variant CYP2C genotype, low baseline neutrophil and thrombocyte counts and female sex were clinically relevant risk factors of dose-limiting myelosuppression (RR $>1.1$ ). A dosing strategy was developed to optimize treatment for patient subgroups. Conclusions This study has identified covariates related to an increased risk of myelosuppression after indisulam therapy. Dose individualization may contribute to treatment optimization.
\end{abstract}

A. S. Zandvliet · J. H. Beijnen · A. D. R. Huitema ( $ه)$

Department of Pharmacy and Pharmacology, The Netherlands Cancer Institute/Slotervaart Hospital, Louwesweg 6, 1066 EC Amsterdam, The Netherlands

e-mail: alwin.huitema@slz.nl

J. H. M. Schellens · J. H. Beijnen

Beta faculty, Department of Pharmaceutical Sciences, Division of Biomedical Analysis, Section of Drug Toxicology, Utrecht University, Utrecht, The Netherlands

J. H. M. Schellens

Department of Clinical Pharmacology, Division of Medical Oncology, The Netherlands Cancer Institute/Antoni van Leeuwenhoek Hospital, Amsterdam, The Netherlands

W. Copalu

Eisai Ltd., London, UK 
Keywords Clinical oncology · Indisulam · Dose individualization · Population pharmacokinetics and pharmacodynamics · Pharmacogenetics . NONMEM

\section{Introduction}

Indisulam is an investigational anticancer agent that has been tested in multiple single agent phase I and II studies. Myelosuppression was the dose limiting toxicity (DLT) in dose escalation studies. Based upon the phase I program, an intravenous 1-h infusion of $700 \mathrm{mg} / \mathrm{m}^{2}$ was considered safe and was recommended for further clinical evaluation [1].

Even though a dose of $700 \mathrm{mg} / \mathrm{m}^{2}$ was well tolerated by most patients, severe hematological toxicity occurred in a subpopulation of patients [2-7]. Both neutropenia and thrombocytopenia were frequently observed. Therapy with indisulam was mainly limited by the occurrence of CTC (Common Toxicity Criteria [8]) grade 4 neutropenia, causing an increased risk of severe or even lifethreatening infections [2-7].

The severity of haematological toxicity after treatment with indisulam showed wide interpatient variability. We hypothesized that patient-related covariates may explain interindividual differences in the severity of haematological toxicity. Identification of relevant patient-related covariates and subsequent dose individualization may reduce differences in indisulam-induced myelosuppression between patients.

A clear relationship between indisulam pharmacokinetics and its haematological toxicity was previously demonstrated by our group [9]. Consequently, differences in indisulam-induced myelosuppression are partly caused by pharmacokinetic variability. In order to minimize pharmacokinetic variability, the dose of indisulam is calculated based on body surface area (BSA). The benefit of BSA-guided dosing was confirmed in a previous population pharmacokinetic study [10]. In addition, we demonstrated that differences in indisulam pharmacokinetics were partly caused by polymorphisms of CYP2C enzymes [11]. Genetic information may therefore also be used for dose individualisation of indisulam. In the current analysis over the complete data, we evaluated the impact of a large selection of patient-related factors (demographics, physical condition, prior treatment, concomitant medication, CYP2C genotype and biochemistry) on the pharmacokinetic profile of indisulam.

Differences in indisulam-induced myelosuppression may not only be caused by pharmacokinetic variability. Pharmacodynamic variability may also play a major role. Kloft et al. identified several patient-related covariates as risk factors for neutropenia after treatment with taxanes or topoisomerase inhibitors [12]. For indisulam, the impact of patient-related factors on the susceptibility of drug-induced myelosuppression was investigated in this analysis.

Treatment with indisulam can be optimized by a priori identification of patients at risk of severe myelosuppression. Subsequent dose individualization may (1) prevent unnecessarily high risks of haematological DLT for more susceptible 
patients and (2) allow treatment with relatively high doses of indisulam for patients who are less susceptible for haematological toxicity, which may be beneficial for treatment efficacy. The aims of this study were (1) to investigate the impact of patient-related covariates on pharmacokinetic and pharmacodynamic parameters related to indisulam-induced hematological toxicity, (2) to identify patients at risk of developing severe myelosuppression and (3) to develop an algorithm for dose individualization of indisulam and to validate this algorithm in silico.

\section{Methods}

Patients and data

Data from 7 phase I studies and 6 phase II studies were used (Table 1). Study protocols were approved by the Medical Ethical Committees and all patients gave written informed consent. Indisulam was administered in various schedules (Table 1). Indisulam concentrations were measured in plasma, red blood cells (RBC) and plasma ultrafiltrate. High-performance liquid chromatography methods with UV detection were used for quantification of indisulam [10, 13]. The assays were validated for the concentration range $0.02-50 \mathrm{mg} / \mathrm{l}$. Assay accuracy and precision were acceptable $(<18.8 \%)$. Absolute neutrophil counts and thrombocyte counts were determined twice weekly during the entire treatment course. All treatment cycles that were monitored for pharmacokinetics and pharmacodynamics were included in the current analysis.

\section{Data analysis}

All analyses were performed using NONMEM software (version V, double precision, level 1.1) (Globomax LLC, Hanover, USA) [14]. The First-Order Conditional Estimation (FOCE) method of NONMEM with interaction (INTER) between the interindividual and residual random effects was the method of choice, but this resulted in unacceptably long run times (multiple weeks). Therefore, the First-Order (FO) method was used to fit logarithmically transformed concentration time data (both drug concentrations and blood cell concentrations, see Eq. 5). Discrimination between hierarchical models was based on the objective function value (OFV) of NONMEM using the likelihood ratio test [14].

Pharmacokinetic and pharmacodynamic data were analyzed sequentially. The pharmacodynamic parameters were estimated conditional on the previously estimated population pharmacokinetic parameters and the pharmacokinetic data. This method has been described in detail by Zhang et al. [15].

The final pharmacokinetic and pharmacodynamic model was used in simulation studies to assess the relative risk of haematological DLT for various patientrelated covariates and to develop an algorithm for dose individualization (see below). 
Table 1 Overview of all studies included in the covariate analysis

\begin{tabular}{|c|c|c|c|c|c|c|c|}
\hline Study & Phase & $\begin{array}{l}\text { Number of } \\
\text { patients }^{\mathrm{a}}\end{array}$ & Patient selection & Drug administration $^{\mathrm{b}}$ & $\begin{array}{l}\text { Number } \\
\text { of PK } \\
\text { samples }\end{array}$ & $\begin{array}{l}\text { Dose } \\
\left(\mathrm{mg} / \mathrm{m}^{2}\right)\end{array}$ & Ref. \\
\hline 1 & I & 40 & Solid tumours & 1-h infusion, day 1 & 15 & $50-1,000$ & [1] \\
\hline 2 & I & 35 & Solid tumours & 1-h infusion, days $1-5$ & 30 & $10-200$ & [25] \\
\hline 3 & I & 46 & Solid tumours & $\begin{array}{l}\text { 1-h infusion, days } 1,8, \\
15 \text { and } 22 \text {, every } \\
6 \text { weeks }\end{array}$ & 31 & $40-500$ & [26] \\
\hline 4 & I & 29 & Solid tumours & Continuous $120-\mathrm{h}$ inf. & 18 & $6-200$ & [27] \\
\hline $5^{\mathrm{d}}$ & I & 21 & Solid tumours & 1- or 2-h infusion & 33 & $400-900$ & [13] \\
\hline 6 & II & 49 & Colorectal cancer & $\begin{array}{l}\text { 1-h infusion, day } 1 \text { or } \\
1 \text {-h infusion, days } 1-5\end{array}$ & 11 & 700 & [2] \\
\hline 7 & II & 44 & $\begin{array}{l}\text { Non-small cell } \\
\text { lung cancer }\end{array}$ & $\begin{array}{l}\text { 1-h infusion, day } 1 \text { or } \\
1 \text {-h infusion, days } 1-5\end{array}$ & 9 & 700 & [3] \\
\hline 8 & II & 15 & $\begin{array}{l}\text { Head and neck } \\
\text { squamous cell } \\
\text { carcinoma }\end{array}$ & 1-h infusion, day 1 & 10 & 700 & [4] \\
\hline 9 & II & 25 & Breast cancer & 1-h infusion, day 1 & 7 & 700 & [5] \\
\hline 10 & II & 28 & Melanoma & 1-h infusion, day 1 & 6 & 700 & [6] \\
\hline 11 & II & 30 & Renal cell cancer & 1-h infusion, day 1 & 14 & 700 & [7] \\
\hline 12 & I & 34 & Colorectal cancer & $\begin{array}{l}\text { 1-h infusion, day } 1 \\
+ \text { capecitabine }\end{array}$ & 18 & $350-800$ & [28] \\
\hline 13 & I & 16 & Solid tumours & $\begin{array}{l}\text { 1-h infusion, day } 1 \\
+ \text { carboplatin }\end{array}$ & 14 & $350-600$ & [29] \\
\hline
\end{tabular}

\footnotetext{
${ }^{a}$ Number of patients of whom pharmacokinetic and haematological data were available

$\mathrm{b}$ Indisulam was administered as mono-therapy every 3 weeks, unless indicated otherwise

c Average number of indisulam PK samples per pharmacokinetically evaluable patient

d Indisulam concentrations were measured in plasma, red blood cells and plasma ultrafiltrate in study 5 . In all other studies, indisulam concentrations were measured in plasma only
}

\section{Basic pharmacokinetic and pharmacodynamic model}

Semi-physiological models of indisulam pharmacokinetics and its hematological toxicity have been developed $[9,16]$. This pharmacokinetic model consisted of four semi-physiological compartments: plasma (PL), RBC, interstitial fluid (IF) and tissue (TIS) (Fig. 1). Indisulam was saturably bound to plasma proteins in plasma and in IF ( $\left.\mathrm{B}_{\max P L}, \mathrm{~K}_{\mathrm{D} \text { PL }}, \mathrm{B}_{\max I F}, \mathrm{~K}_{\mathrm{D}} \mathrm{IF}\right)$, to carbonic anhydrase in $\mathrm{RBC}$ $\left(\mathrm{B}_{\max \mathrm{RBC}}, \mathrm{K}_{\mathrm{D} \text { RBC }}\right.$ ) and to tissue components ( $\mathrm{B}_{\max } \mathrm{TIS}, \mathrm{K}_{\mathrm{D} \text { TIS }}$ ). In addition, indisulam was non-specifically bound to RBC and tissue components ( $\left.\mathrm{N}_{\mathrm{RBC}}, \mathrm{N}_{\mathrm{TIS}}\right)$. Distribution between plasma and RBC was described by the intercompartmental clearance $\mathrm{Q}_{\mathrm{PL}-\mathrm{RBC}}$. The data did not contain sufficient information in order to precisely estimate the intercompartmental clearance between plasma and IF. Instead, the distribution between plasma and IF could be well described by an instantaneous equilibrium. Drug elimination was described by two parallel 


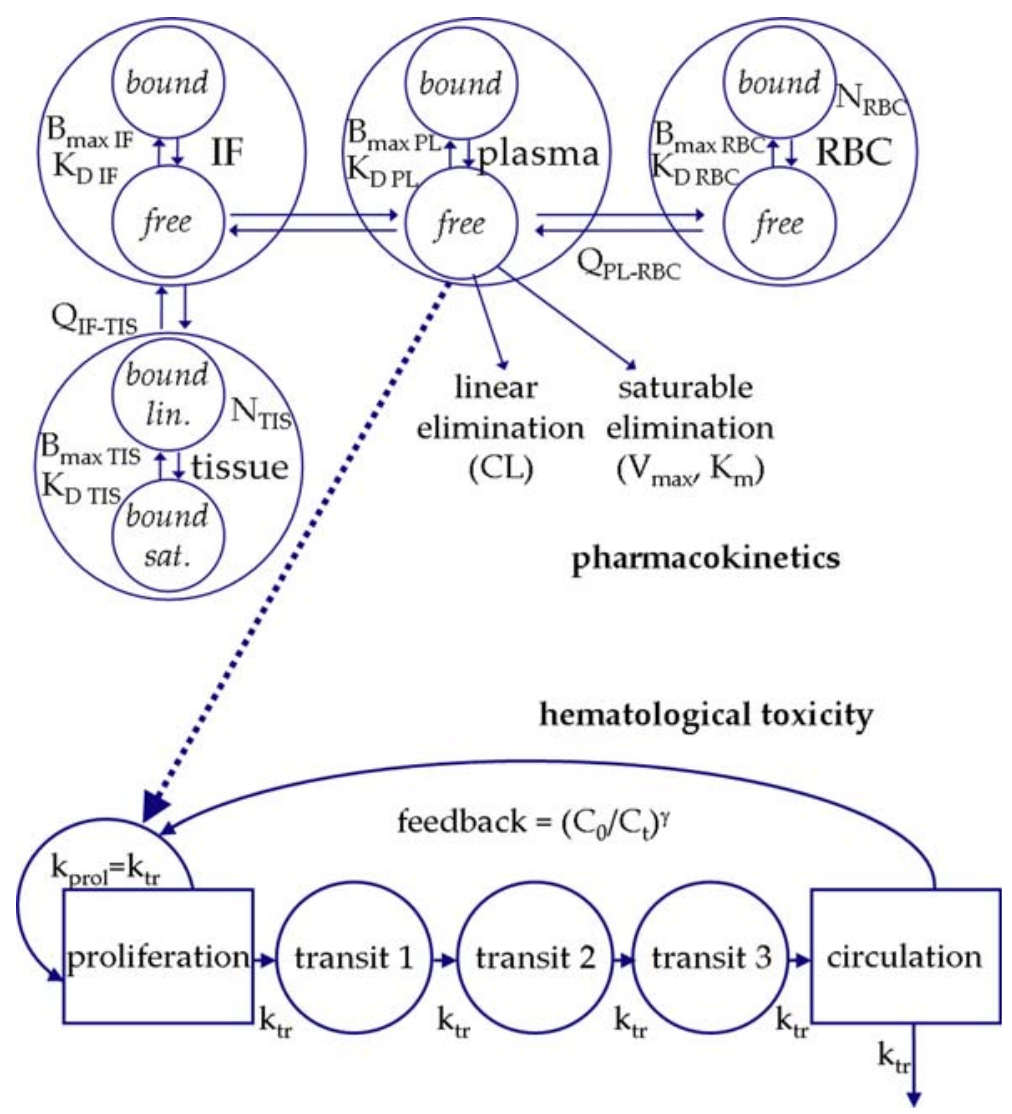

Fig. 1 Graphical representation of the pharmacokinetic and pharmacodynamic model of indisulam. The dashed arrow corresponds to the myelosuppressive effect. $\mathrm{B}_{\max }$ : maximal specific binding capacity; $\mathrm{K}_{\mathrm{D}}$ : equilibrium dissociation constant; $\mathrm{N}$ : non-specific binding constant; $\mathrm{Q}$ : intercompartmental clearance; CL: clearance; $\mathrm{V}_{\max }$ : Michaelis Menten maximal elimination rate; $\mathrm{K}_{\mathrm{m}}$ : Michaelis Menten constant; $\mathrm{k}_{\mathrm{prol}}$ : proliferation rate constant of progenitor blood cells; $\mathrm{k}_{\mathrm{tr}}$ : transition rate constant

pathways: a linear elimination pathway (CL) and a saturable Michaelis Menten pathway $\left(\mathrm{V}_{\max }, \mathrm{K}_{\mathrm{m}}\right)$.

The volumes of blood (calculated from gender and body surface area), RBC and plasma (calculated from the blood volume and hematocrit) and IF (calculated from body weight) were based on relationships that were supported by previous publications $[17,18]$. As indisulam was saturably bound to albumin, the maximal binding capacity of indisulam in plasma and in IF was related to the albumin level. The albumin level in IF was assumed to be $50 \%$ of the plasma albumin level [16]. The basic pharmacokinetic model of indisulam included these physiological-based covariate relationships, but was free of any empirically determined covariate relationships.

The basic pharmacokinetic model of indisulam also comprised an interaction model of a pharmacokinetic drug-drug interaction with capecitabine. Indisulam 
elimination was reduced by concomitant treatment with capecitabine. A metabolite of capecitabine probably inhibits the synthesis of active CYP2C9 enzyme. An interaction model was previously developed to describe the effect of capecitabine on indisulam pharmacokinetics [19]. Briefly, an enzyme turnover model of five sequential transit compartments was used to account for the drug-drug interaction between indisulam and capecitabine for patients who were included in study 12 . The input into the enzyme turnover model was blocked during treatment with capecitabine, which resulted in a reduction of the amount a active enzyme and a consequent reduction of the saturable elimination rate of indisulam. The mean transit time of the enzyme (MTT enzyme ) was estimated [19].

A model of haematological toxicity was used to describe the time profiles of neutrophils and thrombocytes. This model comprised a progenitor compartment of proliferating blood cells, three transit compartments representing maturation chain in the bone marrow and a compartment corresponding to the central circulation (Fig. 1). The first-order rate constant for the transition between the transit compartments is represented by $\mathrm{k}_{\mathrm{tr}}$. The proliferation rate constant $\mathrm{k}_{\text {prol }}$ was equal to $\mathrm{k}_{\mathrm{tr}}$ in this model. A feedback mechanism was included, which represents the effect of the release of endogenous growth factors as a response to the decrease of cells in the systemic circulation. This mechanism influences the proliferation rate and was incorporated in the model according to a power function of the ratio between the cell count at baseline $\left(\mathrm{C}_{0}\right)$ and the cell count at time $\mathrm{t}(\mathrm{Ct})$, according to $\left(\mathrm{C}_{0} / \mathrm{Ct}\right)^{\gamma}$, where $\gamma$ is the estimated parameter of the feedback mechanism. This model was linked to the pharmacokinetic model by a linear function (slope $\mathrm{x} \mathrm{C}_{\text {indisulam}}$ ) that corresponded to the inhibition of cell proliferation by indisulam [9].

The previously published pharmacokinetic and pharmacodynamic models have been developed using data from five phase I studies. In the current analysis, data from eight additional studies were available. Therefore, the basic model could be further developed prior to the covariate analysis. The structural pharmacokinetic model as presented in Fig. 1 was re-evaluated. For the link function between $\mathrm{C}_{\text {indisulam }}$ and the inhibition of cell proliferation (slope $\times \mathrm{C}_{\text {indisulam), the free }}$ concentration of indisulam in plasma was used, as opposed to the total plasma concentration. Baseline neutrophil and thrombocyte counts were estimated from the last measurement that was performed prior to the first administration of study treatment.

\section{Covariate analysis}

Potentially relevant covariates were tested to be related to pharmacokinetic and/or pharmacodynamic parameters of indisulam. A pre-specified analysis plan was used. Only covariate relationships that were considered plausible were evaluated (Table 2). For instance, we investigated the effect of the concomitant use of granulocyte colony-stimulating factor (G-CSF) on the turnover time of blood cells, on the cytotoxic effect of indisulam and most importantly on the feedback parameter gamma, which represented the effect of endogenous growth factors. Prior treatment might have resulted in bone marrow damage and thus might be related to pharmacodynamic parameters. Concomitant use of inductors and inhibitors of the 
Table 2 Patient-related covariates that were tested for their impact on the PK/PD parameter of interest

\begin{tabular}{|c|c|c|c|}
\hline Covariate & \multicolumn{2}{|c|}{$\begin{array}{l}\text { Observed values in } \\
\text { study population }(n=412)\end{array}$} & $\begin{array}{l}\text { PK/PD parameter } \\
\text { of interest }\end{array}$ \\
\hline \multicolumn{4}{|l|}{ Physical condition } \\
\hline \multirow[t]{3}{*}{ Ascites } & Yes & 44 & $\mathrm{~V}_{\mathrm{ISF}}, \mathrm{CL}, \mathrm{V}_{\max }$ \\
\hline & No & 330 & \\
\hline & Missing & 38 & \\
\hline \multirow[t]{3}{*}{ Liver metastates } & Yes & 133 & $\mathrm{CL}, \mathrm{V}_{\max }$ \\
\hline & No & 238 & \\
\hline & Missing & 41 & \\
\hline \multirow{4}{*}{$\begin{array}{l}\text { ECOG performance status [30] } \\
\quad(=\text { W.H.O. score })\end{array}$} & 0 & 190 & PK parameters ${ }^{\mathrm{a}}$ and \\
\hline & 1 & 179 & PD parameters ${ }^{\mathrm{b}}$ \\
\hline & 2 & 27 & \\
\hline & Missing & 16 & \\
\hline \multicolumn{4}{|l|}{ Demographics } \\
\hline \multirow[t]{5}{*}{ Race } & Caucasian & 347 & PK parameters ${ }^{\mathrm{a}}$ \\
\hline & Japanese/Oriental & 24 & \\
\hline & Hispanic & 6 & \\
\hline & Black & 7 & \\
\hline & Missing & 28 & \\
\hline \multirow[t]{2}{*}{$\operatorname{Sex}$} & Male & 229 & PK parameters ${ }^{\mathrm{a}}$ and \\
\hline & Female & 183 & PD parameters ${ }^{\mathrm{b}}$ \\
\hline \multirow[t]{2}{*}{ Age (years) } & Range & $19-82$ & PK parameters ${ }^{\mathrm{a}}$ and \\
\hline & Median & 57 & PD parameters ${ }^{\mathrm{b}}$ \\
\hline \multirow[t]{2}{*}{ Weight (kg) } & Range & $41-145$ & PK parameters ${ }^{\mathrm{a}}$ \\
\hline & Median & 69 & \\
\hline \multirow[t]{2}{*}{ Height $(\mathrm{cm})$} & Range & $145-203$ & PK parameters ${ }^{\mathrm{a}}$ \\
\hline & Median & 168 & \\
\hline \multirow[t]{2}{*}{ Body surface area ${ }^{c}\left(m^{2}\right)$} & Range & $1.33-2.44$ & PK parameters ${ }^{\mathrm{a}}$ \\
\hline & Median & 1.78 & \\
\hline \multicolumn{4}{|l|}{ Prior treatment } \\
\hline \multirow[t]{3}{*}{ Radiotherapy } & Yes & 166 & PD parameters ${ }^{\mathrm{b}}$ \\
\hline & No & 224 & \\
\hline & Missing & 22 & \\
\hline \multirow{4}{*}{$\begin{array}{l}\text { Prior chemotherapy } \\
\quad \text { (number of courses) }\end{array}$} & 0 & 94 & PD parameters ${ }^{\mathrm{b}}$ \\
\hline & 1 or 2 & 209 & \\
\hline & 3 or more & 88 & \\
\hline & Missing & 21 & \\
\hline \multirow[t]{3}{*}{ Prior platinum-based chemotherapy } & Yes & 155 & PD parameters ${ }^{\mathrm{b}}$ \\
\hline & No & 231 & \\
\hline & Missing & 26 & \\
\hline
\end{tabular}


Table 2 continued

\begin{tabular}{|c|c|c|c|}
\hline Covariate & \multicolumn{2}{|c|}{$\begin{array}{l}\text { Observed values in } \\
\text { study population }(n=412)\end{array}$} & $\begin{array}{l}\text { PK/PD parameter } \\
\text { of interest }\end{array}$ \\
\hline \multicolumn{4}{|l|}{ Concomitant medication } \\
\hline \multirow[t]{3}{*}{ G-CSF } & Yes & 9 & PD parameters ${ }^{\mathrm{b}}$ \\
\hline & No & 382 & \\
\hline & Missing & 21 & \\
\hline \multirow[t]{3}{*}{ CYP2C inductors ${ }^{\mathrm{f}}$} & Yes & 60 & $\mathrm{CL}, \mathrm{V}_{\max }$ \\
\hline & No & 331 & \\
\hline & Missing & 21 & \\
\hline \multirow[t]{3}{*}{ CYP2C inhibitors ${ }^{\mathrm{f}}$} & Yes & 116 & $\mathrm{CL}, \mathrm{V}_{\max }$ \\
\hline & No & 275 & \\
\hline & Missing & 21 & \\
\hline \multicolumn{4}{|l|}{ Genotype } \\
\hline \multirow[t]{4}{*}{ CYP2C9 (*3 polymorphism) } & Wildtype & 53 & $\mathrm{CL}, \mathrm{V}_{\max }$ \\
\hline & Heterozygous & 11 & \\
\hline & Homozygous & 1 & \\
\hline & Missing & 347 & \\
\hline \multirow[t]{4}{*}{ CYP2C19 (*2 and $* 3$ polymorphism) } & Wildtype & 43 & $\mathrm{CL}, \mathrm{V}_{\max }$ \\
\hline & Heterozygous & 17 & \\
\hline & Homozygous & 5 & \\
\hline & Missing & 347 & \\
\hline \multicolumn{4}{|l|}{ Blood chemistry } \\
\hline \multirow[t]{3}{*}{ ALAT (U/l) } & Range $^{\mathrm{e}}$ & $5-114$ & $\mathrm{CL}, \mathrm{V}_{\max }$ \\
\hline & Median & 19 & \\
\hline & Missing & $n=31$ & \\
\hline \multirow[t]{3}{*}{ Bilirubin (umol/l) } & Range $^{\mathrm{e}}$ & $3.0-21$ & $\mathrm{CL}, \mathrm{V}_{\max }$ \\
\hline & Median & 8.0 & \\
\hline & Missing & $n=30$ & \\
\hline \multirow[t]{3}{*}{ Creatinine clearance $^{\mathrm{d}}(\mathrm{ml} / \mathrm{min})$} & Range $^{\mathrm{e}}$ & $45-155$ & $\mathrm{CL}, \mathrm{V}_{\max }$ \\
\hline & Median & 82 & \\
\hline & Missing & $n=30$ & \\
\hline
\end{tabular}

${ }^{a}$ PK parameters describing tissue distribution and drug elimination $\left(\mathrm{Q}_{\text {IF-TIS }}, \mathrm{N}_{\mathrm{TIS}}, \mathrm{B}_{\max }\right.$ TIS, $\mathrm{K}_{\mathrm{D} \text { TIS }}$, $\mathrm{V}_{\max }, \mathrm{CL}$ )

b PD parameters for neutrophils (NEU) and platelets (PLT), describing the mean transit time (MTT NEU, $\mathrm{MTT}_{\mathrm{PLT}}$ ), the impact of the positive feedback mechanism (gamma (gEU $_{\text {, gamma }}$ PLT $)$ and the cytotoxic potency of indisulam ( slope $_{\mathrm{NEU}}$, slope $_{\mathrm{PLT}}$ )

c Calculated from weight and height according to the Dubois-Dubois formula

${ }^{\mathrm{d}}$ Calculated from sex, age, weight and serum creatinine according to the Cockcroft-Gault formula

e Range was reported as the 2.5-97.5 percentiles in order to exclude outliers

${ }^{\mathrm{f}}$ Cytochrome P450 inductors and inhibitors were selected according to the Cytochrome P450 DrugInteraction Table from the Indiana University Department of Medicine. [http://medicine.iupui.edu/ flockhart/table.htm] 
cytochrome P450 2C enzymes and genetic variation of these enzymes might have impact on the biotransformation of indisulam. Demographic covariates were related to pharmacokinetic and pharmacodynamic parameters.

Selection of covariate relationships was based on statistical significance using the likelihood ratio test. Covariate effects that were significant at a level of 0.05 in univariate analysis were included into an intermediate model. The significance level during backward elimination was more strict $(P<0.001)$.

For covariate effects included in the model after backward elimination (pre-final model), the contribution of each patient to the difference in OFV (between the prefinal model with and without the covariate effect of interest) was calculated. These individual differences in the OFVs were used as a tool to identify patients having a large impact on the difference in OFV for the covariate effect of interest [20]. Covariate relationships that were driven by single or very few patients were excluded from the pre-final model, which resulted in the final model.

Dichotomous (DI), ordinal (OR) and continuous (CO) variables were tested and the respective covariate relationships were defined according to Eqs. 1, 2 and 3, respectively. Dichotomous variables were either 0 or $1 . P_{\text {pop }}$ was the typical population value of parameter $P$ and $P_{\mathrm{g}}$ corresponded to the typical value of $P$ for the gth group of individuals with identical covariate values. The value of the covariate factor $\mathrm{CF}$ determined how strong $P$ was influenced by the covariate.

$$
\begin{gathered}
P_{\mathrm{g}}=P_{\mathrm{pop}} \cdot(1+\mathrm{CF})^{D I g} \\
P_{\mathrm{g}}=P_{\text {pop }} \cdot\left(1+\mathrm{CF} \cdot \mathrm{OR}_{\mathrm{g}}\right) \\
P_{\mathrm{g}}=P_{\text {pop }} \cdot\left[\frac{\mathrm{CO}_{\mathrm{g}}}{\text { median } \mathrm{CO}}\right]^{\mathrm{CF}}
\end{gathered}
$$

Missing covariates

Patients with missing categorical covariates were considered as an additional subgroup with their own typical parameter value. For instance, during evaluation of the covariate 'liver metastates', three subgroups were identified (liver metastases: yes, liver metastases: no, liver metastases: unknown/missing), which resulted in a model with two extra typical effects. Missing continuous covariates were estimated from log-normal distributions. The geometric mean and variance of missing covariates were assumed to be identical to the geometric mean and variance of observed continuous covariate values.

\section{Random effect models}

Variances of random differences between individuals in each pharmacokinetic parameter were estimated using exponential models (Eq. 4). In this equation, $P_{\mathrm{i}}$ represents the value of parameter $P$ for the $i$ th individual, $P_{\mathrm{g}}$ is the typical group value and $\eta$ is the interindividual random effect with mean 0 and variance $\omega^{2}$. 


$$
P_{\mathrm{i}}=P_{\mathrm{g}} \cdot e^{\eta i}
$$

Differences between observed and individual predicted concentrations (both drug concentrations and blood cell concentrations), resulting from measurement error and model misspecification, were also regarded as random effects and were modeled as exponential errors using:

$$
\ln \left(C_{\text {obsij }}\right)=\ln \left(C_{\text {predij }}\right)+\varepsilon_{\text {ij }}
$$

where $\varepsilon$ is the residual error with mean 0 and variance $\sigma^{2}$, representing the difference between the natural logarithm of the $j$ th observed concentration in the $i$ th individual $\left(\ln \left(C_{\text {obs ij }}\right)\right)$ and its respective prediction $\left(\ln \left(C_{\text {pred ij }}\right)\right)$. The variances of the residual errors of baseline neutrophil and thrombocyte counts and the variances of the residual errors of post-treatment neutrophil and thrombocyte counts were assumed to be identical, respectively.

\section{Clinical relevance}

Statistically significant covariates were tested for clinical relevance. The risk of haematological DLT, defined as neutropenia CTC grade 4 during $>7$ days and/or thrombocytopenia CTC grade 4, was used to assess clinical relevance. Groups of patients were simulated to determine the relative risk of haematological DLT for each covariate after administration of $700 \mathrm{mg} / \mathrm{m}^{2}$ indisulam in a 1-h infusion. The covariate in question was set to the 2.5 percentile (group 1), the 50 percentile (group 2) or the 97.5 percentile (group 3) of the observed covariate values. The other covariates corresponded to the observed covariates in the study population. Each observed combination $(n=412)$ was used 10 times in each simulated group. Consequently, each group comprised 4,120 patients. The relative risks of group 1 and 3 were defined as the ratios between the frequencies of haematological DLT in group 1 or 3 , and the frequency of haematological DLT in group 2. A covariate effect was considered clinically relevant if the relative risk of haematological DLT after treatment with $700 \mathrm{mg} / \mathrm{m}^{2}$ indisulam was estimated to be less than 0.9 or more than 1.1 for either group 1 or group 3.

For a group size of 4,120 patients, the complete $95 \%$ confidence interval of the simulated relative risk was between 0.9 and 1.1 for covariates with no effect on clinical outcome. For covariates that were related to a $20 \%$ change in the risk of haematological DLT, the $95 \%$ confidence interval of the simulated relative risk was completely below 0.9 or completely above 1.1 . Therefore, this strategy guaranteed exclusion of covariates with no effect on clinical outcome (confidence level $>0.95$ ) and selection of covariates that were related to a $20 \%$ change in the risk of haematological DLT (power $>0.95$ ).

In this simulation study, each patient-related covariate was individually assessed for its relative risk of dose limiting myelosuppression. However, independent evaluation of body size measures (i.e. weight WT, height HT, body surface area BSA) would have resulted in simulation of subjects with impossible combinations of covariate values, for instance high WT, high HT and low BSA. To prevent this, 
highly correlated body size measures evaluated simultaneously, which resulted in a relative risk for small (WT $=42 \mathrm{~kg}$ and $\mathrm{BSA}=1.42 \mathrm{~m}^{2}$ ) and large $(\mathrm{WT}=109 \mathrm{~kg}$ and $\mathrm{BSA}=2.25 \mathrm{~m}^{2}$ ) body size.

\section{Identification of patients at risk}

The final model, including all covariates that were statistically significant, was applied to identify patients at risk. In this part of the simulation study, the impact of real-life combinations of covariates (e.g. female sex, Japanese race, small body size, CYP2C19*1/*3 genotype) was assessed in contrast to an evaluation of single covariate. To avoid bias caused by correlation between the various patient-related covariates, only combinations of covariates that were observed in the study population $(n=412)$ were taken into consideration. Using the observed combinations of patient-related covariates, 412 groups of 1,000 patients were simulated to receive $700 \mathrm{mg} / \mathrm{m}^{2}$ indisulam in a $1-\mathrm{h}$ infusion. The overall absolute risk of haematological DLT was defined as the proportion of patients who experienced neutropenia CTC grade 4 during $>7$ days and/or thrombocytopenia CTC grade 4 . The group size of 1,000 patients guaranteed a small relative standard error of the risk simulation ( 0.05 for a proportion of 0.3 ). The 412 combinations of covariates were ranked according to the risk of haematological DLT. Covariate values of patients 1-41 (top 10\%) were compared to the covariate values of patients 372-412 (lower 10\%) in order to verify which covariates were related to high or low risk of haematological DLT. The relationships between each covariate and the risk of haematological DLT were visualized in scatter plots.

\section{Algorithm for dose individualization}

A selection of clinically relevant covariates was included in the dosing algorithm. The covariate values of each patient were used to define a score and an individualized dose. Covariate values that were related to an increased risk of haematological DLT required a dose reduction and covariate values that were related to a reduced risk required a dose increment. In a step-wise process, various possible algorithms for dose individualization were evaluated by the same method that was used to identify patients at risk. Using the observed combinations of patient-related covariates, 412 groups of 1,000 patients were simulated to receive an individualized dose of indisulam in a 1-h infusion. Thus, each of the 412 observed combinations was used to randomly draw 1,000 patients from the population PK-PD model, the PK-PD profiles after indisulam treatment were simulated and haematological toxicities were scored. In each step, correlations between the risk of haematological DLT and the relevant covariates were assessed. If a correlation was still present, the corresponding dose adjustment was increased in the next step. If the direction of a correlation was inversed, the corresponding dose adjustment was reduced in the next step. The algorithm for dose individualization resulting in (1) an acceptable overall absolute risk of haematological DLT for oncology clinical practice of $33 \%$ and (2) minimization of the correlation between each patient characteristic and the risk of haematological DLT was finally selected. 


\section{Results}

\section{Patients and data}

Pharmacokinetic and hematological measurements were available from 412 patients. The 412 patients received a total of 1,263 treatment cycles (median: 2 cycles). Treatment duration varied from 1 day to 26 months. In total, 6,349 indisulam concentrations in plasma were measured in 594 treatment cycles. In a subgroup of 21 patients, 308 concentrations of indisulam were determined in RBC and 42 in plasma ultrafiltrate. 2,669 Absolute neutrophil counts and 2,762 thrombocyte counts were available from all patients. The data set was considerably larger than the data set that was used for a previously published pharmacokinetic analysis of indisulam [16].

Optimization of basic pharmacokinetic and pharmacodynamic model

The pharmacokinetic model was improved with the addition of an extra peripheral compartment $(\triangle \mathrm{OFV}=-760)$. The concentration of albumin in the extra peripheral compartment was assumed to be the same as in IF. The intercompartmental clearance between the IF compartment and the extra peripheral compartment was large $(771 \mathrm{l} / \mathrm{h})$. The volume of distribution was estimated at $19.3 \mathrm{l}$.

The relationship between indisulam pharmacokinetics and the inhibition of cell proliferation was modeled by a linear function (slope $\times \mathrm{C}_{\text {indisulam}}$ ). The likelihood of the model increased $(\triangle \mathrm{OFV}=-8)$ when total plasma concentrations were replaced with free plasma concentrations of indisulam, while the total number of estimated parameters remained unchanged. The relationship between indisulam pharmacokinetics and the inhibition of cell proliferation was also included as an Emax model, but Emax and $\mathrm{EC}_{50}$ values could not be estimated independently.

Sequential analysis of pharmacokinetic and pharmacodynamic data was justified by the results since the empirical Bayesian estimates of the pharmacokinetic parameters were very similar for the pharmacokinetic model and the pharmacokinetic-pharmacodynamic model.

\section{Patient-related covariates}

Table 2 lists the frequencies and observed ranges of the patient-related covariates that were evaluated in this covariate analysis. Data on physical condition, demographics, prior treatment, concomitant medication and clinical chemistry parameters could be retrieved for the majority of the patients. For each covariate, Table 2 indicates the number of patients with an unknown value. Genotype data were available for patients who participated in studies 5, 12 and 13 (Table 1). Baseline neutrophil counts (median $5.3 \times 10^{9} / 1$, missing $n=51$ ) and baseline thrombocyte counts $\left(287 \times 10^{9} / 1\right.$, missing $\left.n=42\right)$ were part of the basic models of neutropenia and thrombocytopenia. 
Covariate selection for pharmacokinetic parameters

Out of 61 covariate relationships that were tested in univariate analyses, 28 were statistically significant. Six covariate relationships remained after backward elimination. The pharmacokinetic parameter estimates of the final model are listed in Table 3. More details of the significant covariate relationships are presented in Table 4.

Both the linear and the saturable elimination rates of indisulam were related to measures of body size. The linear clearance (CL) of indisulam was significantly related to body weight $\left(\mathrm{CL}_{\mathrm{g}}=\mathrm{CL}_{\mathrm{pop}} \cdot[\mathrm{WT} / 69]^{\mathrm{CF}}\right.$, see Eq. 3). The covariate factor CF was not significantly different from 0.75 , which is in accordance with allometric scaling [21]. Patients with a BSA of $2.1 \mathrm{~m}^{2}$ had a $22 \%$ larger $\mathrm{V}_{\max }$ than patients with median BSA. The maximal elimination rate $\mathrm{V}_{\max }$ was reduced by $31 \%$ for heterozygous CYP2C9*3 mutations and the linear clearance was reduced by $49 \%$ for heterozygous $* 2$ or $* 3$ mutations in the gene encoding for CYP2C19. As expected, the typical values of $\mathrm{V}_{\max }$ and the linear clearance for patients with unknown genotype were between the values for wildtype patients and patients with a variant genotype. Caucasian patients had a $61 \%$ larger $\mathrm{V}_{\max }$ than Japanese patients. Body weight was inversely related to specific binding of indisulam in body tissue.

In addition, ascites was borderline significantly related to the clearance of indisulam. The impact of ascites on indisulam pharmacokinetics could be accounted for by an increased distribution volume of indisulam for patients with ascites, but the volume of the extra peripheral compartment was not different for patients with and without ascites.

Covariate selection for pharmacodynamic parameters

Table 3 shows the pharmacodynamic parameter estimates of the final model and the covariate relationships that were statistically significant are listed in Table 4. The turnover time of neutrophils and thrombocytes was shorter for females than for males. Prior chemotherapy was related to higher sensitivity of neutrophils to the cytotoxic effect of indisulam.

Concomitant use of granulocyte colony stimulating factor (G-CSF) did not significantly affect the feedback parameter gamma of neutrophils. Unexpectedly, patients who were treated with G-CSF were significantly more susceptible to the myelosuppressive effect of indisulam. This should not be interpreted as a causal relationship, since it is very unlikely that treatment with G-CSF caused an increase in haematological toxicity of indisulam. The observed relationship is rather due to selection bias: patients who were susceptible for the haematological effects of indisulam were more likely to be treated with G-CSF (see discussion). It was concluded that the design of this study was not suitable to investigate the effect of G-CSF on haematological toxicity. Hence, the impact of G-CSF treatment on clinical outcome was not further investigated in simulation studies.

The statistical covariate analysis suggested that the cytotoxic potency of indisulam for thrombocytes was reduced in older patients $(\Delta \mathrm{OFV}=-17)$. 
Table 3 Parameter estimates of the final pharmacokinetic and pharmacodynamic model

\begin{tabular}{lll}
\hline & $\begin{array}{l}\text { Typical } \\
\text { value }\end{array}$ & $\begin{array}{l}\text { Inter- } \\
\text { individual error (of typical } \\
\text { variability value) }\end{array}$ \\
\hline
\end{tabular}

Pharmacokinetic model

$\mathrm{B}_{\max } \mathrm{PL} \quad$ Binding capacity PL protein $\quad(\mathrm{mg} / \mathrm{l}) \quad$ [albumin $]_{\mathrm{PL}}$

$\begin{array}{lll}\mathrm{K}_{\mathrm{D}} \mathrm{PL} & \text { Dissociation constant PL } \quad(\mathrm{mg} / \mathrm{l}) \quad 0.25^{\mathrm{b}}\end{array}$ protein (fixed)

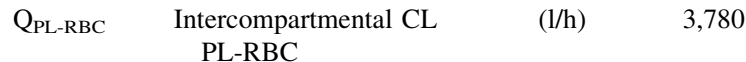

$9.4 \%$

$\mathrm{N}_{\mathrm{RBC}} \quad$ Non-specific binding const.

91.8

$8.5 \%$

$\mathrm{B}_{\max \mathrm{RBC}}$ RBC

$\mathrm{K}_{\mathrm{D} \text { RBC }} \quad$ Dissociation constant RBC

$(\mathrm{mg} / \mathrm{l})$

57.9

$27 \%$

$7.5 \%$

$\mathrm{B}_{\max \text { IF }}$

Binding capacity IF

(mg/1)

0.00260

$8.5 \%$

(mg/l) $\quad \mathrm{B}_{\max } \mathrm{PL}$

$50 \%^{\mathrm{c}}$

(fixed)

K $\quad$ Dissociation constant IF $\quad(\mathrm{mg} / \mathrm{l}) \quad 0.25^{\mathrm{b}}$

(fixed)

Q IF-TIS Intercompartmental CL IF-TIS (1/h)

$2,630 \quad 70 \% \quad 11 \%$

$\mathrm{N}_{\text {TIS }} \quad$ Non-specific binding const.

$\begin{array}{lll}9.74 & 87 \% & 80 \%\end{array}$

$\mathrm{B}_{\max }$ TIS TIS

$\mathrm{K}_{\mathrm{D}}$ TIS

Binding capacity TIS

$(\mathrm{mg} / \mathrm{l})$

5.79

$61 \%$

$15 \%$

QIF-periph.

Dissociation constant TIS

(mg/l)

0.0261

$64 \%$

Intercompartmental CL

(1/h)

771

$13 \%$

$\mathrm{V}_{\text {periph. }} \quad$ Volume peripheral

(1)

19.3

$8.7 \%$

$\mathrm{V}_{\max }$ compartment

$\mathrm{K}_{\mathrm{m}}$

Maximal elimination rate

(mg/h)

4.30

$52 \%$

$12 \%$

CL

Michaelis Menten constant

(mg/l)

0.0013

$18 \%$

(1/h)

132

$18 \%$

MTT $_{\text {enzyme }}$

Plasma clearance

(h)

195

$31 \%$

$0.7 \%$

Pharmacodynamic model

\begin{tabular}{|c|c|c|c|c|c|}
\hline $\mathrm{MTT}_{\text {neu }}$ & Mean transit time neutrophils & (h) & 134 & $33 \%$ & $\mathrm{NE}$ \\
\hline Gamma $_{\text {neu }}$ & $\begin{array}{l}\text { Feedback parameter } \\
\text { neutrophils }\end{array}$ & & 0.157 & $20 \%$ & $\mathrm{NE}$ \\
\hline Slope $_{\text {neu }}$ & $\begin{array}{l}\text { Cytotoxic potency for } \\
\text { neutrophils }\end{array}$ & $(1 / \mathrm{mg})^{\mathrm{a}}$ & 16.4 & $87 \%$ & $\mathrm{NE}$ \\
\hline $\mathrm{MTT}_{\mathrm{plt}}$ & Mean transit time platelets & (h) & 105 & $21 \%$ & $\mathrm{NE}$ \\
\hline Gamma $_{\text {plt }}$ & Feedback parameter platelets & & 0.165 & $46 \%$ & $\mathrm{NE}$ \\
\hline Slope $_{\text {plt }}$ & Cytotoxic potency for platelets & $(1 / \mathrm{mg})^{\mathrm{a}}$ & 10.7 & $120 \%$ & $\mathrm{NE}$ \\
\hline$\rho_{\text {slope neu } \sim \text { plt }}$ & $\begin{array}{l}\text { Correlation coefficient } \\
\text { between slope } \\
\text { slope }_{\text {plt }} \text { and }\end{array}$ & & 0.92 & & $\mathrm{NE}$ \\
\hline \multicolumn{6}{|l|}{ Residual error } \\
\hline $\mathrm{C}_{\mathrm{PL} \text { total }}$ & Total plasma conc. indisulam & $(\%)$ & 33 & & \\
\hline
\end{tabular}


Table 3 continued

\begin{tabular}{|c|c|c|c|c|c|}
\hline & & & $\begin{array}{l}\text { Typical } \\
\text { value }\end{array}$ & $\begin{array}{l}\text { Inter- } \\
\text { individual } \\
\text { variability }\end{array}$ & $\begin{array}{l}\text { Relative standard } \\
\text { error (of typical } \\
\text { value) }\end{array}$ \\
\hline $\mathrm{C}_{\mathrm{PL} \text { free }}$ & Free plasma conc. indisulam & $(\%)$ & 38 & & \\
\hline $\mathrm{C}_{\mathrm{RBC}}$ & Conc. indisulam in erythrocytes & $(\%)$ & 11 & & \\
\hline ANC & Absolute neutrophil count & $(\%)$ & 37 & & \\
\hline $\mathrm{TC}$ & Thrombocyte count & $(\%)$ & 27 & & \\
\hline
\end{tabular}

$N E$ not evaluated

a Based on free plasma concentrations of indisulam

b The equilibrium dissociation constant was determined in a previous non-dynamic analysis [31]

c The albumin concentration in interstitial fluid was assumed to be $50 \%$ of the plasma level [32]

However, the individual difference in the OFV was large for one patient $(\triangle \mathrm{IOFV}=-25)$ and very small for the other 411 patients. This demonstrated that the effect of age on the inhibition of cell proliferation was driven by a single patient and this relationship was not taken into account in further simulation studies.

\section{Clinical relevance}

The relative risk was larger than 1.1 for female patients $(\mathrm{RR}=1.18)$ as well as for patients from Japanese origin $(R R=1.19)$, with small body size $(R R=1.13$ for $\mathrm{WT}=45 \mathrm{~kg}$ and $\left.\mathrm{BSA}=1.42 \mathrm{~m}^{2}\right)$, with a variant CYP2C9 genotype $(\mathrm{RR}=1.38$ for homozygous CYP2C9*3 mutants) and with a variant CYP2C19 genotype $(\mathrm{RR}=2.34$ for homozygous CYP2C19*2 or $* 3$ mutants) (Table 4$)$. Despite the fact that a BSA-based dosing strategy was employed, body size had a moderate impact on the risk of haematological DLT after a $700 \mathrm{mg} / \mathrm{m}^{2}$ dose (RR $=1.13$ for $\mathrm{WT}=45 \mathrm{~kg}$ and $\mathrm{BSA}=1.42 \mathrm{~m}^{2}$ ). Prior chemotherapy did not lead to a clinically relevant increase in risk of toxicity (Table 4).

Identification of patients at risk

The overall absolute risk of haematological DLT at the first cycle of treatment with $700 \mathrm{mg} / \mathrm{m}^{2}$ indisulam was 0.32 . Despite BSA-based dosing $\left(700 \mathrm{mg} / \mathrm{m}^{2}\right)$, the $10 \%$ patients with the highest risk of dose limiting myelosuppression had a smaller body size as compared to the $10 \%$ lowest risk patients (Fig. 2a, b). High risk patients also had lower baseline blood cell counts (Fig. 2c, d). Moreover, the high risk group comprised more female (34 vs. 12) and Japanese patients (14 vs. 0) than the low risk group and more high risk patients had one or more CYP2C19 mutations (13 vs. 1).

The patient with the lowest risk of dose limiting haematological toxicity was a Caucasian male patient with large body size $\left(B S A=2.23 \mathrm{~m}^{2}\right.$, weight $=119 \mathrm{~kg}$ ) and a wildtype CYP2C genotype. The patient with the highest risk was a Japanese female patient with small body size $\left(\mathrm{BSA}=1.4 \mathrm{~m}^{2}\right.$, weight $=47 \mathrm{~kg}$ ) who was homozygous for the CYP2C19*2 mutation. 
Table 4 Statistically significant covariate relationships and their clinical relevance

\begin{tabular}{|c|c|c|c|}
\hline & $\begin{array}{l}\text { Related } \\
\text { parameter }^{\mathrm{g}}\end{array}$ & Covariate effect & $\begin{array}{l}\text { Relative risk (RR) of dose limiting } \\
\text { haematological toxicity }\end{array}$ \\
\hline \multicolumn{4}{|l|}{ Pharmacokinetic covariates } \\
\hline Body surface area $\left(\mathrm{m}^{2}\right)$ & $\mathrm{V}_{\max }$ & $(\mathrm{BSA} / 1.78)^{1.20}$ & $\mathrm{BSA}=1.42 / \mathrm{WT}=45 \rightarrow \mathrm{RR}=1.13$ \\
\hline Race $^{\mathrm{e}}$ & $\mathrm{V}_{\max }$ & $(1+0.613)^{\text {race }}$ & Japanese $\rightarrow \mathrm{RR}=1.19$ \\
\hline WT (kg) & $\mathrm{CL}$ & $(\mathrm{WT} / 69)^{0.75}$ & $\mathrm{WT}=45 / \mathrm{BSA}=1.42 \rightarrow \mathrm{RR}=1.13$ \\
\hline WT (kg) & $\mathrm{B}_{\max }$ TIS & $(\mathrm{WT} / 69)^{-0.621}$ & $\mathrm{WT}=45 / \mathrm{BSA}=1.42 \rightarrow \mathrm{RR}=1.13$ \\
\hline CYP2C9 $* 3$ polymorphism ${ }^{\mathrm{d}}$ & $\mathrm{V}_{\max }$ & $(1-0.309 \cdot \mathrm{MUT})$ & $\begin{array}{l}\text { Heterozygous } \rightarrow \mathrm{RR}=1.15 \\
\text { homozygous } \rightarrow \mathrm{RR}=1.38\end{array}$ \\
\hline $\begin{array}{l}\text { CYP2C19 } * 2 / * 3 \\
\text { polymorphism }^{\text {d }}\end{array}$ & $\mathrm{CL}$ & $(1-0.487 \cdot \mathrm{MUT})$ & $\begin{array}{l}\text { Heterozygous } \rightarrow \mathrm{RR}=1.45 \\
\text { homozygous } \rightarrow \mathrm{RR}=2.34\end{array}$ \\
\hline \multicolumn{4}{|l|}{ Pharmacodynamic covariates } \\
\hline $\operatorname{Sex}^{\mathrm{b}}$ & $\mathrm{MTT}_{\text {neu }}$ & $(1+0.225)^{\mathrm{sex}}$ & Female $\rightarrow \mathrm{RR}=1.18$ \\
\hline $\mathrm{G}-\mathrm{CSF}^{\mathrm{a}}$ & $\mathrm{MTT}_{\text {neu }}$ & $(1-0.263)^{\mathrm{G}-\mathrm{CSF}}$ & Not evaluated ${ }^{\mathrm{f}}$ \\
\hline $\mathrm{G}-\mathrm{CSF}^{\mathrm{a}}$ & Slope $_{\text {neu }}$ & $(1+1.04)^{\mathrm{G}-\mathrm{CSF}}$ & Not evaluated ${ }^{\mathrm{f}}$ \\
\hline Prior chemotherapy $\left(\mathrm{PC}^{\mathrm{c}}\right)$ & Slope $_{\text {neu }}$ & $(1+\mathrm{PC} \cdot 0.0994)$ & $\mathrm{PC}=2 \rightarrow \mathrm{RR}=1.06$ \\
\hline $\operatorname{Sex}^{\mathrm{b}}$ & $\mathrm{MTT}_{\mathrm{plt}}$ & $(1+0.214)^{\operatorname{sex}}$ & Female $\rightarrow \mathrm{RR}=1.18$ \\
\hline $\mathrm{G}-\mathrm{CSF}^{\mathrm{a}}$ & $\mathrm{MTT}_{\mathrm{plt}}$ & $(1+0.438)^{\mathrm{G}-\mathrm{CSF}}$ & Not evaluated ${ }^{\mathrm{f}}$ \\
\hline $\mathrm{G}-\mathrm{CSF}^{\mathrm{a}}$ & Gamma $_{\text {plt }}$ & $(1+0.422)^{\mathrm{G}-\mathrm{CSF}}$ & Not evaluated ${ }^{\mathrm{f}}$ \\
\hline $\mathrm{G}-\mathrm{CSF}^{\mathrm{a}}$ & Slope $_{\text {plt }}$ & $(1+2.57)^{\mathrm{G}-\mathrm{CSF}}$ & Not evaluated ${ }^{\mathrm{f}}$ \\
\hline Age (years) & Slope $_{\text {plt }}$ & $(\text { age/57) })^{-0.612}$ & Not evaluated ${ }^{\mathrm{f}}$ \\
\hline
\end{tabular}

a $0=$ no; $1=$ yes

${ }^{\text {b }} 0=$ female; 1 = male

c no prior chemotherapy: $\mathrm{PC}=0$; one or two prior courses: $\mathrm{PC}=1$; three or more prior courses: $\mathrm{PC}=2$

${ }^{\mathrm{d}}$ MUT $=$ number of mutated alleles (wildtype: $\mathrm{MUT}=0$; heterozygous: $\mathrm{MUT}=1$; homozygous: MUT = 2)

e $0=$ Japanese; 1 = Caucasian/Hispanic/Black

${ }^{\mathrm{f}}$ low predictive value (see Results-Covariate selection for pharmacodynamic paremeters) and therefore not further evaluated

g $\mathrm{V}_{\max }$ : maximal saturable elimination rate; $\mathrm{CL}$ : clearance; $\mathrm{B}_{\max }$ TIS: maximal binding capacity in tissue; MTT: mean transit time of neutrophils (neu) and platelets (plt); slope: cytotoxic potency of indisulam; gamma: feedback parameter representing the effect of endogenous growth factors

\section{Algorithm for dose individualization}

The clinically relevant patient-related covariates were considered for inclusion into the dosing strategy. Baseline platelet and neutrophil counts were correlated and it was therefore sufficient to only include the baseline neutrophil count into the dosing algorithm. The correlation between the risk of haematological DLT and body size measures was weaker after BSA-based dosing than after weight-based dosing. Hence, BSA-based dosing was superior over weight-based dosing. Female and 

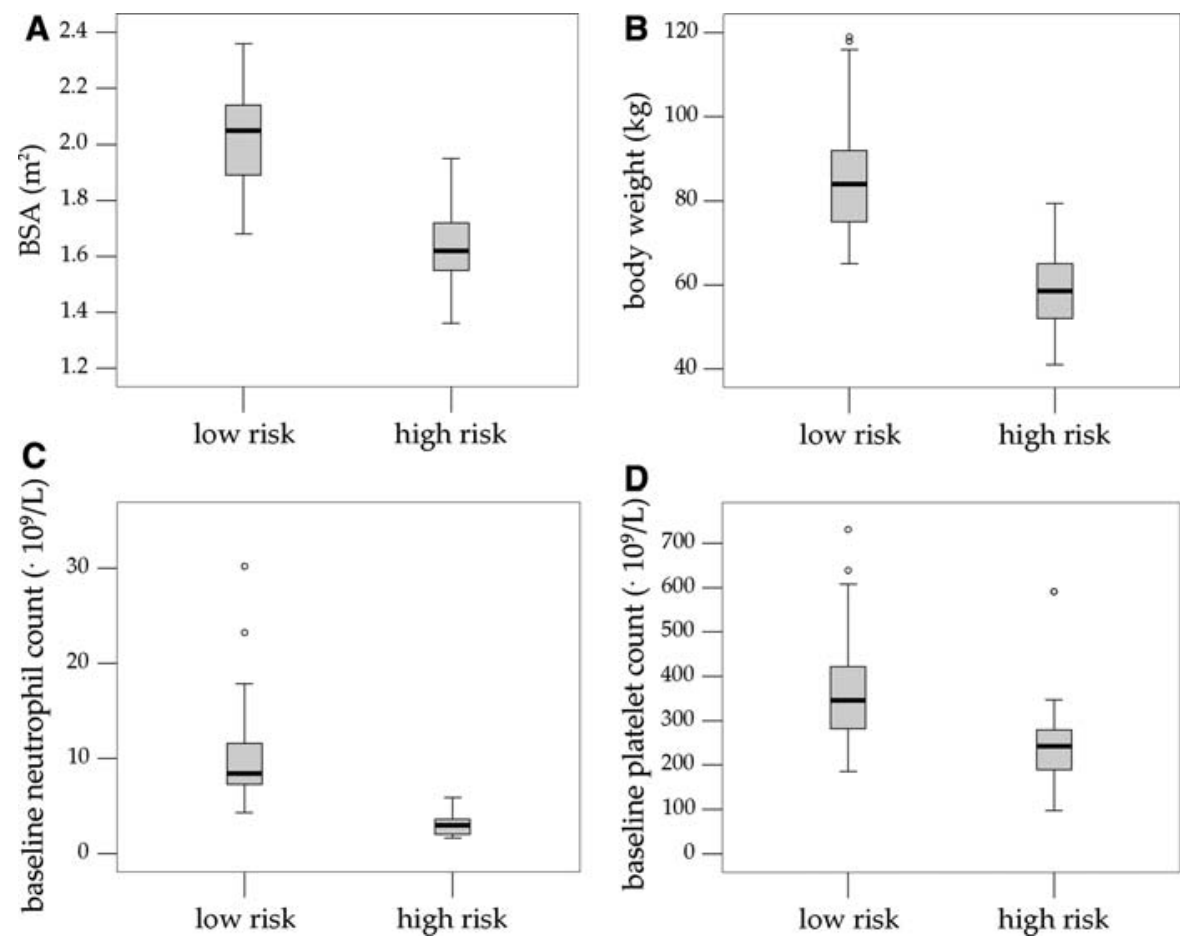

Fig. 2 Box-and-whisker diagrams of covariates in the 10\% highest and the $10 \%$ lowest risk patients after treatment with $700 \mathrm{mg} / \mathrm{m}^{2}$ indisulam administered in a 1-h infusion. Body surface area (a), weight (b), baseline neutrophil count (c) and baseline thrombocyte count (d) were lower in the high risk group. The boxes correspond to the interquartile range (IQR) Q25-Q75 and observations more than $1.5 *$ IQR below Q25 or more than $1.5 *$ IQR above Q75 are indicated (Õ)

Japanese patients required a dose reduction as well as patients with a mutant CYP2C genotype. Table 5 shows the proposed algorithm for dose individualization of indisulam. The proposed indisulam dose for Caucasian male patients with a wildtype CYP2C genotype and a baseline neutrophil count between $4 \times 10^{9} / 1$ and $8 \times 10^{9} / 1$ was $775 \mathrm{mg} / \mathrm{m}^{2}$. Patients with female sex, variant CYP2C genotype, Japanese race and/or a baseline neutrophil count below $4 \times 10^{9} / 1$ required a reduced dose. Conversely, a dose increment was indicated for patients with a baseline neutrophil count above $8 \times 10^{9} / 1$. In Table 5, two examples of the application of the dosing algorithm are presented. A dose of $900 \mathrm{mg} / \mathrm{m}^{2}$ is recommended for a Caucasian male patient with a wildtype genotype and a baseline neutrophil count of $9 \times 10^{9} / 1$ and a dose of $375 \mathrm{mg} / \mathrm{m}^{2}$ is recommended for a Japanese female patient who is homozygous for the CYP2C19*2 mutation. Correlations between risk factors and the risk of severe myelosuppression resolved upon the application of this dosing algorithm (Fig. 3). Figure 4 demonstrates that some patients required a reduced dose of indisulam in order to enhance treatment safety. Conversely, around $50 \%$ of the patients could be treated with a higher dose than the standard $700 \mathrm{mg} / \mathrm{m}^{2}$, which may be beneficial for treatment efficacy. 
Table 5 Algorithm for dose individualization of indisulam

\begin{tabular}{|c|c|c|c|}
\hline Patient characteristic & Score & Example $1^{\mathrm{a}}$ & Example $2^{\mathrm{b}}$ \\
\hline \multicolumn{4}{|l|}{ Sex } \\
\hline Female & -3 & & -3 \\
\hline Male & 0 & 0 & \\
\hline \multicolumn{4}{|l|}{ CYP2C genotype } \\
\hline Wildtype & 0 & 0 & \\
\hline Heterozygous CYP2C9*3 & -2 & & \\
\hline Homozygous CYP2C9*3 & -4 & & \\
\hline Heterozygous CYP2C $19 * 2$ or $* 3$ & -6 & & \\
\hline Homozygous CYP2C $19 * 2$ or $* 3$ & -12 & & -12 \\
\hline \multicolumn{4}{|l|}{ Race } \\
\hline Caucasian & 0 & 0 & \\
\hline Japanese & -1 & & -1 \\
\hline \multicolumn{4}{|l|}{ Baseline neutrophil count } \\
\hline$<4 \times 10^{9} / 1$ & -5 & & \\
\hline$>8 \times 10^{9} / 1$ & +5 & +5 & \\
\hline Total score & & +5 & -16 \\
\hline Individual dose $\left(\mathrm{mg} / \mathrm{m}^{2}\right)$ & $775+$ total score $\cdot 25$ & 900 & 375 \\
\hline
\end{tabular}

${ }^{\text {a }}$ Example 1: application of the dosing algorithm for a Caucasian male patient with a wildtype genotype and a baseline neutrophil count of $9 \times 10^{9} / 1$

b Example 2: application of the dosing algorithm for a Japanese female patient with a *2/*2 genotype for CYP2C19

The overall absolute risk of dose limiting myelosuppression was the same for the original BSA-based dosing strategy (risk $=0.32$ ) and the new dosing algorithm (risk $=0.33$ ). However, the distribution of the individual risk probability for DLT was wider with BSA-based dosing as compared to the new dosing algorithm (Fig. 5). In order to produce Fig. 5, the individual risk of dose limiting myelosuppression was calculated for each of the 412 patients. Patients were ranked from low to high risk, resulting in a patient ranking number (1-412). This number was plotted against the risk of dose limiting haematological toxicity. The distribution was narrowed and the risk of dose limiting myelosuppression was partly equalized by the application of the new dosing algorithm. All patients had a risk between 15\% and 55\% after application of the new dosing strategy, in contrast to the BSA-based dosing where the risk was between $14 \%$ and $78 \%$.

\section{Discussion}

In this study, we evaluated the impact of patient-related covariates on indisulaminduced myelosuppression. Patients with low neutrophil counts and/or polymorphisms of the gene encoding for the CYP2C enzymes had an increased risk of haematological DLT after treatment with indisulam. Additional risk factors were 

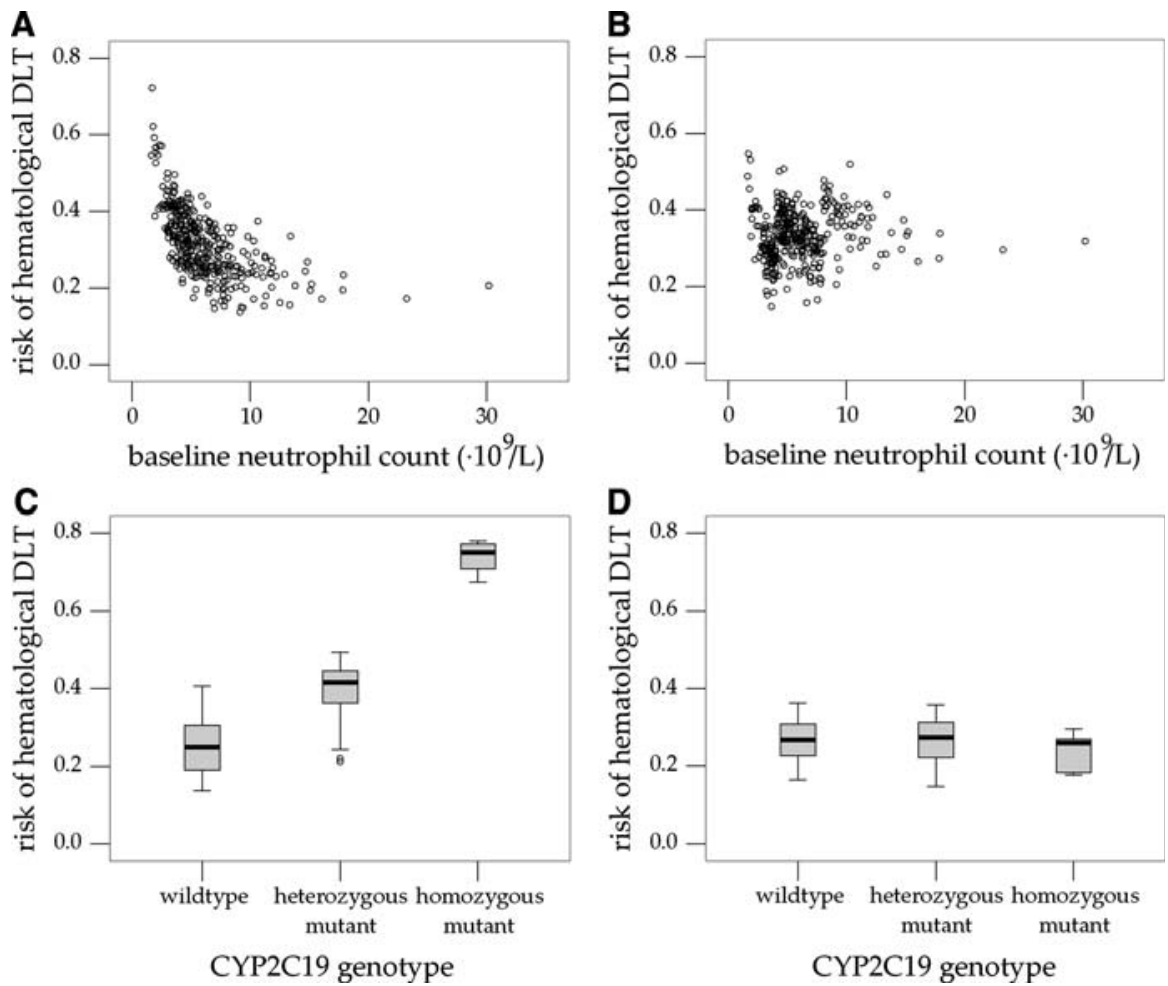

Fig. 3 Plots of the risk of severe myelosuppression versus baseline neutrophil counts a and CYP2C19 genotype $\mathbf{c}$ after treatment with $700 \mathrm{mg} / \mathrm{m}^{2}$ indisulam administered in a $1-\mathrm{h}$ infusion. $\mathbf{b}$ and $\mathbf{d}$ show the corresponding plots after application of the dosing algorithm

female sex and Japanese race. These risk factors were included into a dosing algorithm for individualization of treatment with indisulam.

The baseline neutrophil count was identified as the most important characteristic for dose individualization of indisulam. Neutrophil counts are determined as routine clinical practice prior to chemotherapy. If these cell counts are below predefined criteria, a dose delay may be indicated. This study shows that neutrophil counts can not only be used to determine whether a patient's condition allows treatment with indisulam, but also to define which dose is required for treatment optimization.

In this study, it was assumed that patients are optimally treated by the highest safe dose of indisulam. This assumption seems reasonable for the cell cycle inhibitor indisulam, but future studies to further investigate the relationship between drug exposure and antitumour effect are warranted.

The impact of CYP2C polymorphisms on the risk of myelosuppression was previously investigated by our group. In this previous study, the CYP2C9*3 polymorphism was significantly related to a reduced maximal elimination rate $\left(\mathrm{V}_{\max }\right)$ of indisulam [11]. Concurrent treatment with capecitabine was also related to a reduction of $\mathrm{V}_{\max }$ [19]. In the current analysis over the complete data, the effect of 

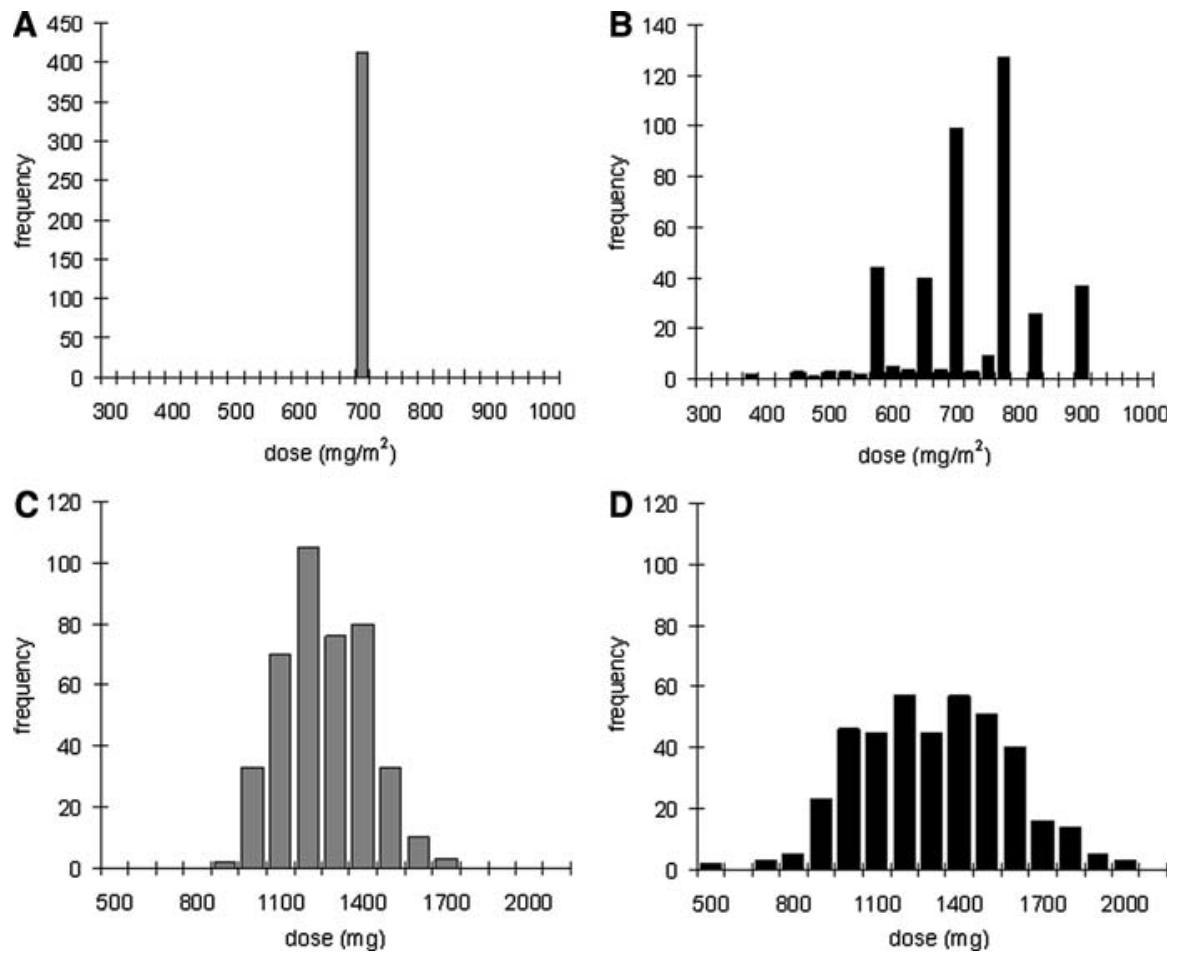

Fig. 4 Distribution of individual indisulam doses for BSA-based dosing $\square$ (a and c) and for the dosing algorithm (b and d) calculated for each of the 412 patients in the study population, in $\mathrm{mg} / \mathrm{m}^{2}$ (a and b) and as an absolute dose after correction for body surface area (c and $\mathbf{d}$ )

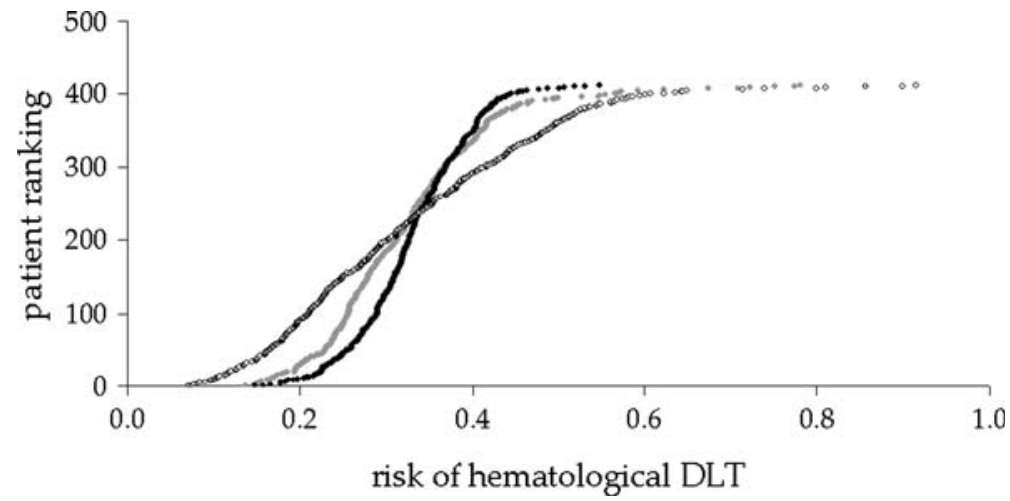

Fig. 5 The distribution of the risk probability for the study population $(n=412)$ for flat dosing $(\bigcirc)$, BSA-based dosing (O) and for the dosing algorithm ( ). Patients were ranked from low risk (lower left) to high risk (upper right). The application of the dosing algorithm resulted in a more uniform distribution of the risk, which resulted in a steeper curve 
the CYP2C9*3 mutation was not statistically significant due to correlation of CYP2C9 genotype and concomitant use of capecitabine in the study population.

High body weight was related to low maximal binding capacity of indisulam in body tissue. Although the exact nature of specific and non-specific binding of indisulam to tissue components is unknown, our results imply that the binding capacity of fat tissue is lower than the binding capacity of lean body tissue. High body weight was also related to high indisulam clearance. The $3 / 4$ power law of allometric scaling was successfully applied to include this effect into the covariate model [21].

The effect of G-CSF on neutropenia was previously demonstrated by Kloft et al. [12]. For neutrophil counts, the feedback parameter gamma was increased in patients who received G-CSF after chemotherapy. This effect was not demonstrated in the current study. Conversely, the cytotoxic effect of indisulam was relatively high in patients who were treated with G-CSF. This observation is most likely due to selection bias: patients who were very sensitive to the cytotoxic effect of indisulam were treated with G-CSF on medical indication.

In the previously published models of chemotherapy-induced neutropenia and thrombocytopenia, the cytotoxic effect of anticancer drugs was related to total plasma concentrations. In the current study, however, the cytotoxic effect of indisulam was considered proportional to its free plasma concentrations. This consideration was in accordance with the free-drug hypothesis, which suggests that only free drug in plasma determines in vivo drug effects. This has been demonstrated for several drugs, such as lidocaine and beta-receptor antagonists [22, 23]. For indisulam, the likelihood of the myelosuppression model was increased indeed when free plasma concentrations of indisulam were used instead of total plasma concentrations.

Special consideration was given to the problem of missing covariates in this analysis. It was attempted to estimate missing covariates from a mixture model (nominal data) and from log-normal distributions (continuous data). Unfortunately, the mixture method resulted in unacceptably long run times. Therefore, an extra typical parameter value was estimated for patient subgroups with missing covariates in order to avoid bias.

Parameter estimates generally corresponded well to previously reported values $[9,24]$ This indicates that the parameter estimates were largely independent of the estimation method in NONMEM, which supports the adequacy of the FO method for this analysis.

Patient-related covariates might not always have a large impact in univariate analyses, but might become relevant in combination with other patient-related covariates. Therefore, the evaluation of interaction terms of covariate effects was considered. This resulted in model over-parameterization. Yet, we took co-linearity between covariate effects into account by using only observed combinations of patient-related covariates in the simulation studies.

A dosing algorithm was developed to promote safety and efficacy of treatment with indisulam. A Japanese female patient with a CYP2C19*2/*2 genotype will have an acceptable risk of dose limiting myelosuppression after treatment with a reduced dose of $375 \mathrm{mg} / \mathrm{m}^{2}$ indisulam. A Caucasian male patient with a wildtype genotype and a baseline neutrophil count of $9 \times 10^{9} / 1$ can be optimally treated with a dose of $900 \mathrm{mg} / \mathrm{m}^{2}$. 
The proposed dosing algorithm is expected to result in a risk of haematological DLT between $15 \%$ and $55 \%$ for all patients. Complete equalization of the risk of haematological DLT would have required a much more complex dosing algorithm. This is related to the highly non-linear pharmacokinetic profile of indisulam. The proposed dosing algorithm was selected as the optimal algorithm, given that it should be feasible for implementation in clinical practice.

In conclusion, this study has identified patient-related covariates related to an increased risk of haematological adverse effects after therapy with indisulam. Dose individualization based on these patient-related covariates might result in safer treatment for high risk patients and more effective treatment with higher doses for low risk patients. Dose individualization using the proposed algorithm may contribute to optimization of treatment with indisulam.

Acknowledgements This research was supported by a grant from the Eisai network of companies.

Open Access This article is distributed under the terms of the Creative Commons Attribution Noncommercial License which permits any noncommercial use, distribution, and reproduction in any medium, provided the original author(s) and source are credited.

\section{References}

1. Raymond E, ten Bokkel Huinink WW, Taieb J, Beijnen JH, Faivre S, Wanders J, Ravic M, Fumoleau P, Armand JP, Schellens JHM (2002) Phase I and pharmacokinetic study of E7070, a novel chloroindolyl sulfonamide cell-cycle inhibitor, administered as a one-hour infusion every three weeks in patients with advanced cancer. J Clin Oncol 20(16):3508-3521. doi:10.1200/JCO.2002.09.030

2. Mainwaring PN, Van Cutsem E, Van Laethem JL, Propper D, Twelves C, Bridgewater J, Audhuy B, Carmichael J, Punt CJA, Cassidy J, Stuart N, Ravic M (2002) A multicentre randomised phase II study of E7070 in patients with colorectal cancer who have failed 5-fluorouracil-based chemotherapy. Proc Am Soc Clin Oncol 21:153a Abstract

3. Talbot DC, von Pawel J, Cattell E, Yule SM, Johnston C, Zandvliet AS, Huitema ADR, Norbury CJ, Ellis P, Bosquee L, Reck M (2007) A randomized phase II pharmacokinetic and pharmacodynamic study of indisulam as second-line therapy in patients with advanced non-small cell lung cancer. Clin Cancer Res 13(6):1816-1822. doi:10.1158/1078-0432.CCR-06-0249

4. Haddad RI, Weinstein LJ, Wieczorek TJ, Bhattacharya N, Raftopoulos H, Oster MW, Zhang X, Latham VM Jr, Costello R, Faucher JL, DeRosa C, Yule SM, Miller LP, Loda M, Posner MR, Shapiro GI (2004) A phase II clinical and pharmacodynamic study of E7070 in patients with metastatic, recurrent, or refractory squamous cell carcinoma of the head and neck: modulation of retinoblastoma protein phosphorylation by a novel chloroindolyl sulfonamide cell cycle inhibitor. Clin Cancer Res 10(14):4680-4687. doi:10.1158/1078-0432.CCR-04-0229

5. Fumoleau P, Viens P, Cottu PH, De Grève J, Marty M, Delaloge S, Miles D, O’Reilly S, Wardley A, Schmid P, Ravic M, Paternoster M (2003) A multi center phase II study of E7070, a chloroindolylsulfonamide anticancer agent in anthracycline and taxane pre treated breast cancer. 26th San Antonio breast cancer symposium (abstract)

6. Smyth JF, Aamdal S, Awada A, Dittrich C, Caponigro F, Schoffski P, Gore M, Lesimple T, Djurasinovic N, Baron B, Ravic M, Fumoleau P, Punt CJ (2005) Phase II study of E7070 in patients with metastatic melanoma. Ann Oncol 16(1):158-161. doi:10.1093/annonc/mdi016

7. Raftopoulos H, Escudier B, Renshaw G, Lara PN, Dutcher J, Nanus D, Petrylak DP, Sacris L (2004) A phase II multicenter study of the cyclin-dependent kinase inhibitor indisulam in patients with inoperable and/or metastatic renal cell carcinoma (RCC). J Clin Oncol-ASCO Annual Meeting Proceedings (Post-Meeting Edition) 22(14S):414s (abstract)

8. Cancer Therapy Evaluation Program: Common Toxicity Criteria, Version 2.0, DCTD, NCI, NIH, DHHS (1998) 
9. van Kesteren C, Zandvliet AS, Karlsson MO, Mathôt RAA, Punt CJA, Armand JP, Raymond E, Huitema ADR, Dittrich C, Dumez H, Roche H, Droz JP, Ravic M, Yule SM, Wanders J, Beijnen JH, Fumoleau P, Schellens JHM (2005) Semi-physiological model describing the hematological toxicity of the anti-cancer agent indisulam. Invest New Drugs 23(3):225-234. doi:10.1007/s10637-005-6730-3

10. van Kesteren C, Mathôt RAA, Raymond E, Armand JP, Dittrich C, Dumez H, Roche H, Droz JP, Punt CJA, Ravic M, Wanders J, Beijnen JH, Fumoleau P, Schellens JHM (2002) Population pharmacokinetics of the novel anticancer agent E7070 during four phase I studies: model building and validation. J Clin Oncol 20(19):4065-4073. doi:10.1200/JCO.2002.01.005

11. Zandvliet AS, Huitema ADR, Copalu W, Yamada Y, Tamura T, Beijnen JH, Schellens JHM (2007) CYP2C9 and CYP2C19 polymorphic forms are related to increased indisulam exposure and higher risk of severe hematologic toxicity. Clin Cancer Res 13(10):2970-2976. doi:10.1158/1078-0432. CCR-06-2978

12. Kloft C, Wallin J, Henningsson A, Chatelut E, Karlsson MO (2006) Population pharmacokineticpharmacodynamic model for neutropenia with patient subgroup identification: comparison across anticancer drugs. Clin Cancer Res 12(18):5481-5490. doi:10.1158/1078-0432.CCR-06-0815

13. Yamada Y, Yamamoto N, Shimoyama T, Horiike A, Fujisaka Y, Takayama K, Sakamoto T, Nishioka Y, Yasuda S, Tamura T (2005) Phase I pharmacokinetic and pharmacogenomic study of E7070 administered once every 21 days. Cancer Sci 96(10):721-728. doi:10.1111/j.1349-7006.2005. 00109.x

14. Beal SL, Boeckman AJ, Sheiner LB (1988) NONMEM user's guides. University of California at San Francisco, San Francisco CA

15. Zhang L, Beal SL, Sheiner LB (2003) Simultaneous vs. sequential analysis for population PK/PD data I: best-case performance. J Pharmacokinet Pharmacodyn 30(6):387-404. doi:10.1023/B:JOPA. 0000012998.04442.1f

16. Zandvliet AS, Schellens JHM, Copalu W, Beijnen JH, Huitema ADR (2006) A semi-physiological population pharmacokinetic model describing the non-linear disposition of indisulam. J Pharmacokinet Pharmacodyn 33(5):543-570. doi:10.1007/s10928-006-9021-5

17. Baker RJ, Kozoll DD, Meyer KA (1957) The use of surface area as a basis for establishing normal blood volume. Surg Gynecol Obstet 104(2):183-189

18. Kawai R, Mathew D, Tanaka C, Rowland M (1998) Physiologically based pharmacokinetics of cyclosporine A: extension to tissue distribution kinetics in rats and scale-up to human. J Pharmacol Exp Ther 287(2):457-468

19. Zandvliet AS, Siegel-Lakhai WS, Beijnen JH, Copalu W, Etienne-Grimaldi MC, Milano G, Schellens JH, Huitema AD (2008) PK/PD model of indisulam and capecitabine: interaction causes excessive myelosuppression. Clin Pharmacol Ther 83(6):829-839. doi:10.1038/sj.clpt. 6100344

20. Sadray S, Jonsson EN, Karlsson MO (1999) Likelihood-based diagnostics for influential individuals in non-linear mixed effects model selection. Pharm Res 16(8):1260-1265. doi:10.1023/A:101485 7832337

21. West GB, Brown JH, Enquist BJ (1997) A general model for the origin of allometric scaling laws in biology. Science 276(5309):122-126. doi:10.1126/science.276.5309.122

22. Pieper JA, Wyman MG, Goldreyer BN, Cannon DS, Slaughter RL, Lalka D (1980) Lidocaine toxicity: effects of total versus free lidocaine concentrations. Circulation 62(Suppl.III):181

23. McDevitt DG, Frisk-Holmberg M, Hollifield JW, Shand DG (1976) Plasma binding and the affinity of propranolol for a beta receptor in man. Clin Pharmacol Ther 20(2):152-157

24. Friberg LE, Henningsson A, Maas H, Nguyen L, Karlsson MO (2002) Model of chemotherapyinduced myelosuppression with parameter consistency across drugs. J Clin Oncol 20(24):4713-4721. doi:10.1200/JCO.2002.02.140

25. Punt CJA, Fumoleau P, van de Walle B, Faber MN, Ravic M, Campone M (2001) Phase I and pharmacokinetic study of E7070, a novel sulfonamide, given at a daily times five schedule in patients with solid tumors. A study by the EORTC-early clinical studies group (ECSG). Ann Oncol 12(9):1289-1293. doi:10.1023/A:1012287111922

26. Dittrich C, Dumez H, Calvert H, Hanauske A, Faber M, Wanders J, Yule SM, Ravic M, Fumoleau P (2003) Phase I and pharmacokinetic study of E7070, a chloroindolyl-sulfonamide anticancer agent, administered on a weekly schedule to patients with solid tumors. Clin Cancer Res 9(14):5195-5204

27. Terret C, Zanetta S, Roche H, Schellens JHM, Faber MN, Wanders J, Ravic M, Droz JP (2003) Phase I clinical and pharmacokinetic study of E7070, a novel sulfonamide given as a 5-day continuous 
infusion repeated every 3 weeks in patients with solid tumours. A study by the EORTC Early Clinical Study Group (ECSG). Eur J Cancer 39(8):1097-1104. doi:10.1016/S0959-8049(03)00128-X

28. Siegel-Lakhai WS, Zandvliet AS, Huitema AD, Tibben MM, Milano G, Girre V, Dieras V, King A, Richmond E, Wanders J, Beijnen JH, Schellens JH (2008) A dose-escalation study of indisulam in combination with capecitabine (Xeloda) in patients with solid tumours. Br J Cancer 98(8):13201326. doi:10.1038/sj.bjc. 6604300

29. Dittrich C, Zandvliet AS, Gneist M, Huitema ADR, King AA, Wanders J (2007) A phase I and pharmacokinetic study of indisulam in combination with carboplatin. Br J Cancer 96(4):559-566. doi:10.1038/sj.bjc.6603606

30. Oken MM, Creech RH, Tormey DC, Horton J, Davis TE, McFadden ET, Carbone PP (1982) Toxicity and response criteria of the Eastern Cooperative Oncology Group. Am J Clin Oncol 5(6):649-655. doi:10.1097/00000421-198212000-00014

31. Zandvliet AS, Copalu W, Schellens JHM, Beijnen JH, Huitema ADR (2006) Saturable binding of indisulam to plasma proteins and distribution to human erythrocytes. Drug Metab Dispos 34(6):1041-1046

32. Morgan GE, Mikhail MS, Murray MJ, Larson CP (2002) Clinical anesthesiology, 3rd edn. McGrawHill, Medical Publishing Division, New York 